\title{
Testing time for Caltrans
}

\section{San Francisco}

A SIMULATED earthquake on a portion of intact freeway and an elaborate computer model of the San Francisco Bay Bridge are among the studies likely to be adopted by California officials in an effort to understand what happened during the 17 October Loma Prieta earthquake. At a meeting scheduled for late last week between representatives from Caltrans, the state transportation department, and University of California engineers, several proposals for roadway studies were due to be debated, but Caltrans spokesman Jim Drag confirmed that the simulated quake and the Bay Bridge studies seemed likely to be approved.

Also last week, California governor George Deukmejian signed 24 earthquake relief measures, including a sales

\section{IMAGE UNAVAILABLE FOR COPYRIGHT REASONS}

tural engineer at the University of California at Berkeley, is to test proposed strengthening techniques for other San Francisco Bay Area double-decker freeways. Three similar roadways in San Francisco that were damaged in the earthquake are still closed.

In the second test, which will alternate with the hydraulic-jack experiment, a pair of vibration generators will be attached to the same freeway section. Attached to the upper deck, the twin 'shakers' rotate heavy weights in opposite directions at a synchronized frequency, so that the centrifugal force is focused in a specific direction along the roadway. The force, of the order of 10,000 pounds, will not be great, but by repeated application at a steady rate it will test the structure's endurance against vibration.

Accelerators attached to the freeway will allow engineers, knowing the mass of the deck, to measure the forces developed in the supporting columns. "If we know the total force in the structure and how it displaces under that force, we can develop a good computer model of the resisting mechanism", says Moehle.

The tests will be finished by Christmas, when the entire freeway span will be Looking south on Interstate 880 on the Tuesday evening. (AP). demolished. Because the tax increase of a quarter-cent per dollar, and officials announced that the Bay Bridge would reopen on 17 November, exactly one month after the quake.

The highway test involves an intact section of Interstate 880 in Oakland, just south of the Cypress Viaduct section which collapsed during the upheaval. Apart from a firmer foundation, the section is almost identical to the portion that collapsed. The prevailing theory is that the upper deck failed because the supporting columns and the joints that bind them with the lower deck had not been adequately reinforced. Two tests will examine these and other ideas.

In one, hydraulic jacks mounted on steel frames under both sides of the roadway will be used to simulate the sideways movement of the 7.1-magnitude quake. An array of electronic instruments and cameras will measure the displacement and strain developed at specific points, and record the physical damage.

The overpass will first be tested in its present condition, after which engineers will reinforce the columns with steel beams, and then slowly bring the freeway to the failing point, which might take as much as three million pounds of force. The objective, says Jack Moehle, a structested section will not be "failed" in its original condition, engineers will have no direct measure of how the Cypress section really collapsed, but the investigators hope that demolition crews will haul a few columns away for further study in the laboratory.

The Bay Bridge study will be confined mainly to laboratory simulations and computer modelling. Faculty and students from the structural engineering programme of UC Berkeley's civil engineering department have alredy been amassing damage information, from notebooks, photographs, videotapes and sketches. They plan to supplement this data with other input to develop a detailed computer model of the bridge that extends even to its underlying soil.

"Our main goal is to make sure our computer programs - simulations, modeling, all the tools that we have to do the analysis - are capable of predicting events like this and damage like this", said Abolhassan Astaneh, a UC Berkeley assistant professor of civil engineering. These studies, he hoped, will enable engineers to recommend specific retrofitting plans and other modifications, so that the bridge can withstand "the big one".

Robert Buderi

\section{Federal policy makes trouble \\ Washington}

MANY examples of "waste, fraud and abuse" in the federal government can be attributed to problems in developing software, according to a report released last week by the US House of Representatives Committee on Science, Space and Technology. On everything from budgeting to intellectual property rights, it says, government policies "have congealed over time in a manner almost perfectly designed to thwart the development of high-quality software".

Although no single action will instantly solve the government's software woes, the committee staff recommends that a working group on improving software development be set up in the president's Office of Science and Technology Policy with the aim of making long-term changes in the government procurement system.

At present, government contracts specify in "excruciating" detail exactly how a system will look at delivery several years in the future, so when the inevitable changes are introduced, software quality is adversely affected and development costs increase.

Reducing overall costs would require spending more time and money in the design stage, when it is much cheaper to correct an error, than in the maintenance phase. But this strategy is discouraged by the process for obtaining congressional approval, which requires initial costs to be minimized.

The report, stemming from an investigation into faulty software in a radiation therapy machine which caused several deaths, also calls on the National Institute of Standards and Technology to play a greater role in improving software evaluation. At present there is no infallible method for assessing quantitatively the safety of software used in, for example, aircraft flight controls or nuclear reactors, in which software flaws can put lives at risk. The federal government's 'software woes" are exacerbated by the staff crisis created by its inability to compete with the private sector in attracting software specialists.

Computer security and ethics also came under scrutiny last week in the House subcommittee of criminal justice, which is considering two bills to increase the penalties for damaging hardware and software as a deterrent to hackers. But researchers and legal experts are divided over the need for new legislation, definitions of "authorized access" and how to increase computer security without restricting free exchange of information. Action on the bills is being delayed pending the outcome of the trial of Robert Morris, the Cornell University graduate student whose 'virus' disabled thousands of computers last year.

Christine McGourty 